\title{
Chronic Morphine Treatment Alters NMDA Receptor-Mediated Synaptic Transmission in the Nucleus Accumbens
}

\author{
Gilles Martin, ${ }^{1}$ Serge H. Ahmed, ${ }^{1}$ Thomas Blank, ${ }^{2}$ Joachim Spiess, ${ }^{2}$ George F. Koob, ${ }^{1}$ and George R. Siggins ${ }^{1}$ \\ ${ }^{1}$ Department of Neuropharmacology, The Scripps Research Institute, La Jolla, California 92037, and 2Department of \\ Molecular Neuroendocrinology, The Max-Planck Institute for Experimental Medicine, Goettingen, Germany
}

In a study of a possible substrate underlying morphine addiction, we examined NMDA receptor-mediated synaptic transmission of core nucleus accumbens neurons after chronic morphine treatment, using intracellular recording in a slice preparation of rat. We evoked pharmacologically isolated NMDA EPSCs by local stimulation and elicited inward currents by NMDA superfusion. In control slices, $\mathrm{Mg}^{2+}$ and phorbol 12,13-diacetate (PDAc), a protein kinase C activator, strongly inhibited and increased, respectively, NMDA EPSC amplitudes. The PDAc effects were likely postsynaptic because PDAc enhanced the currents evoked by superfused NMDA to the same extent that it did the NMDA EPSCs. Chronic morphine treatment significantly decreased NMDA EPSC amplitudes and the sensitivity of NMDA EPSCs to $\mathrm{Mg}^{2+}$ and PDAc, as well as the kinetics of the decay (inactivation rate) of the EPSCs (from $97 \pm$ $2.5 \mathrm{msec}$ in untreated rats to $78.7 \pm 1.8 \mathrm{msec}$ in slices from treated rats). One week after withdrawal, the $\mathrm{Mg}^{2+}$ and PDAc effects were still significantly less than those in control slices. Interestingly, 1 week of withdrawal led to an increased NMDA EPSC inactivation rate compared with controls. These data demonstrate that chronic morphine treatment significantly alters NMDA receptor-mediated synaptic transmission in the accumbens, and these effects persist 1 week after withdrawal. These long-term effects may represent an important neuroadaptation in opiate dependence.

Key words: NMDA glutamate receptors; electrophysiology; phorbol ester; protein kinase C; chronic morphine treatment; kinetics
The nucleus accumbens (NAcc) is regarded as a pivotal brain structure in drug reinforcement (Koob et al., 1992). It receives massive dopamine input from the ventral tegmental area (VTA) and glutamate input from limbic structures such as the hippocampus, prefrontal cortex, and amygdala (for review, see Zahm and Brog, 1992; Groenewegen et al., 1996; Heimer et al., 1997). Whereas dopamine has long been considered a prime candidate mediating the addictive effects of opioids, other findings support the hypothesis that some opioid effects may be mediated directly by dopamine-independent mechanisms (Koob, 1992). Thus, glutamate-mediated synaptic transmission has emerged recently as another putative opiate substrate. Although non-NMDA (Kest et al., 1997) and metabotropic glutamate receptors (Fundytus et al., 1995, 1997; Fundytus and Coderre, 1997; Martin et al., 1999) have received some attention in opiate dependence and tolerance, the role of NMDA receptors (an ionotropic glutamate receptor subtype) has come under considerable scrutiny. Thus, behavioral studies showed that NMDA receptors may control some aspects of morphine tolerance and dependence (Marek et al., 1991; Trujillo and Akil, 1991, 1994; Trujillo, 1995) as well as sensitization (Jeziorski et al., 1994). Other evidence also suggests that NAcc NMDA receptors may be directly involved in opiate effects. Thus, our laboratory found previously that $\mu$-opioid receptors regulate NAcc NMDA EPSPs both pre- and postsynaptically (Martin et al., 1997a). However, the mechanisms underly-

\footnotetext{
Received May 12, 1999; revised Aug. 2, 1999; accepted Aug. 2, 1999.

This research was supported by National Institutes of Health Grants DA03665 and AA06420. We thank Drs. P. Schweitzer and M. Tallent for helpful discussions and criticisms and Mike Arends for critically reading this manuscript.

Correspondence should be addressed to Dr. George Robert Siggins, Department of Neuropharmacology, CVN-12 The Scripps Research Institute, 10550 North Torrey Pines Road, La Jolla, CA 92037.

Copyright (C) 1999 Society for Neuroscience 0270-6474/99/199081-09\$05.00/0
}

ing the possible role of NMDA receptors in opiate-rewarding effects are unknown.

Although still controversial, it is generally believed that NMDA receptors are heteromultimeric channels comprising six subunits (NR1, NR2A-D, and NR3A) identified to date. The NR1 subunit is regarded as the key NMDA receptor subunit (Kutsuwada et al., 1992; Meguro et al., 1992; Monyer et al., 1992; Ishii et al., 1993; Wang and Thukral, 1996). NR2A-D subunits, when coexpressed with NR1, confer distinct pharmacological properties to the NMDA receptor complex and essentially act as regulatory subunits. For example, recombinant NMDA receptors composed of NR1 and NR2A or NR1 and NR2B are much more sensitive to $\mathrm{Mg}^{2+}$ than are those composed of NR1 and NR2C or NR1 and NR2D subunits (Burnashev et al., 1992, 1995; Monyer et al., 1992; Kuner and Schoepfer, 1996). Similarly, the protein kinase C (PKC)-mediated phosphorylation of NMDA receptors (Kutsuwada et al., 1992; Mori et al., 1993), the kinetics of NMDA-evoked currents, and their sensitivity to polyamines (Williams et al., 1994; Gallagher et al., 1996; Takahashi et al., 1996; Flint et al., 1997; Gottmann et al., 1997) all seem to be under the control of NR2A and NR2B subunits.

Interestingly, several findings have suggested that NMDA receptor subunit expression is very sensitive to antipsychotic drugs, as well as to drugs of abuse like alcohol (Follesa and Ticku, 1996; Snell et al., 1996; Chen et al., 1997; Kalluri et al., 1998). Recently, Fitzgerald et al. (1996) reported that chronic morphine treatment increased the levels of NR1 subunits in the VTA. The involvement of discrete NMDA receptor subunits in opiate dependence is supported by a report that antisense oligonucleotides directed against the NR1 subunit attenuated morphine withdrawal signs (Zhu and Ho, 1998). Therefore, in the present study, we tested the hypothesis that chronic morphine treatment alters NMDA 
receptor properties, using intracellular voltage-clamp recording in NAcc slices and pharmacological and kinetic assays designed to help discriminate between different compositions of heteromeric NMDA receptor subunits.

\section{MATERIALS AND METHODS}

Animals and slice preparation. We used male Sprague Dawley rats (100$170 \mathrm{gm}$ ) to prepare NAcc slices from fresh brain tissue, as described previously (Martin et al., 1997b, 1999). The brains were rapidly removed and transferred to cold $\left(4^{\circ} \mathrm{C}\right)$, oxygenated artificial CSF (ACSF) of the following composition (in $\mathrm{mM}$ ): $\mathrm{NaCl}, 130 ; \mathrm{KCl}, 3.5 ; \mathrm{NaH}_{2} \mathrm{PO}_{4}, 1.25$; $\mathrm{MgSO}_{4} \cdot 7 \mathrm{H}_{2} \mathrm{O}, 1.5 ; \mathrm{CaCl}_{2}, 2 ; \mathrm{NaHCO}_{3}, 24$; and glucose, 10 . We glued a tissue block containing NAcc to a Teflon chuck and cut it transversely with a vibroslice cutter (Campden Instruments) and immediately incubated the slices (400 $\mu \mathrm{m}$ thick) in the recording chamber. During initial incubation in an "interface" configuration, the tops of the slices were exposed to a mixture of $\mathrm{O}_{2}(95 \%)$ and $\mathrm{CO}_{2}(5 \%)$. After $30 \mathrm{~min}$, we completely submerged and superfused the slices with warm $\left(34^{\circ} \mathrm{C}\right)$, carbogenated ACSF, at a rate of 3-4 ml/min. Slices from morphinetreated rats were maintained in $1 \mu \mathrm{M}$ morphine throughout experimentation.

Recording. We pulled sharp glass microelectrodes from borosilicate capillary glass (1.2 $\mathrm{mm}$ outer diameter and $0.8 \mathrm{~mm}$ inner diameter) on a Brown-Flaming puller (Sutter Instruments) and filled them with $3 \mathrm{M}$ $\mathrm{KCl}$. Tip resistances were 60-100 $\mathrm{M} \Omega$. We used an Axoclamp 2B amplifier (Axon Instruments) to record neurons in discontinuous singleelectrode voltage-clamp mode. Throughout all experiments we continuously monitored electrode settling time and capacitance neutralization on a separate oscilloscope. Current and voltage levels were monitored and stored on polygraph paper, digitized by a Digidata interface (Axon Instruments), and acquired to a 486 personal computer using Clampex 6.0 software (Axon Instruments). The digitized records then were analyzed with Clampfit and Axograph software (Axon Instruments). We recorded neurons within the core NAcc just ventrally to the anterior commissure. For most of the cells we constructed three-step currentvoltage curves in voltage-clamp mode with the first voltage step $-20 \mathrm{mV}$ negative to the holding potential $(-80 \mathrm{mV})$, with an increment of +20 $\mathrm{mV}$ for the two subsequent steps.

Synaptic stimulation. We studied the NMDA component of EPSCs in voltage-clamp mode, using an $I-V$ protocol (400 msec step duration) to measure EPSC amplitudes evoked at different membrane potentials. The NMDA EPSCs were elicited by local ("focal" or "proximal") stimulation (see below) triggered $100 \mathrm{msec}$ after the onset of, and superimposed on, the voltage pulse. We averaged two traces for each voltage-step size with superimposed NMDA EPSCs. To minimize the influence of stimulation artifacts on the NMDA current, we injected a 2 msec duration pulse into the amplifier-blanking circuitry $1 \mathrm{msec}$ before the stimulation.

We evoked synaptic components through a tungsten bipolar stimulating electrode with a tip separation of $1 \mathrm{~mm}$, placed in the NAcc within 1 $\mathrm{mm}$ of the recording electrode. Stimulation parameters $(7-14 \mathrm{~V} ; 50 \mathrm{msec}$ pulse duration; $0.1 \mathrm{~Hz}$ ) were chosen to generate sizable (near halfmaximal) and reproducible NMDA EPSCs without spiking, and the stimulus intensity then was maintained constant throughout the recording period. The analysis of the NMDA EPSC amplitudes involved setting one cursor $1 \mathrm{msec}$ before the stimulation artifact and the other at the peak of the response. We measured the inactivation rate via Clampfit software (Axon Instruments), by setting the first cursor at the peak amplitude and the second one $260 \mathrm{msec}$ later. A single exponential (Chebychev method) was used to fit the response and obtain the time to decay.

Drug administration. To isolate the NMDA EPSC component pharmacologically, we superfused the slices with antagonists specific for nonNMDA (kainate and AMPA) glutamate receptors (10 $\mu \mathrm{M} \mathrm{CNQX)} \mathrm{and}$ $\mathrm{GABA}_{\mathrm{A}}$ receptors (15 $\mu \mathrm{M}$ bicuculline), for at least one-half hour before study. The identity of the isolated component was determined by superfusing the NMDA receptor antagonist D-APV $(60 \mu \mathrm{M})$ at the end of some experiments (see Martin et al., 1997a, 1999). In other studies, to test for postsynaptic phorbol 12,13-diacetate (PDAc) effects, we superfused NMDA in the presence of $1 \mu \mathrm{M}$ TTX to minimize presynaptic effects (in addition to CNQX and bicuculline). We purchased CNQX and PDAc from Research Biochemicals (Natick, MA) and D-APV and NMDA from Sigma (St. Louis, MO).

Induction of morphine dependence and withdrawal. Rats were made dependent by subcutaneous implantation of morphine pellets $(75 \mathrm{mg}$ of

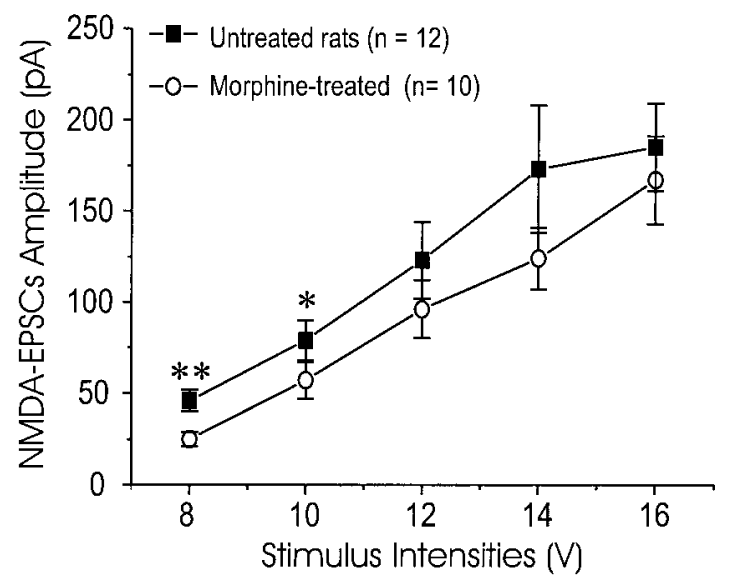

Figure 1. Chronic morphine treatment reduces the amplitude of NMDA EPSCs. Input-output curves. Mean NMDA EPSC amplitudes in NAcc neurons from untreated $(n=12)$ and morphine-treated $(n=10)$ rats over an equivalent range of stimulus intensities are shown. Note that the reduction of the amplitude is relatively homogenous throughout the range of stimulus intensities, although only the effects at the two lowest intensities $(8$ and $10 \mathrm{~V})$ were significant $\left({ }^{* *} p<0.001 ;{ }^{*} p<0.05\right)$.

base) provided by the National Institute on Drug Abuse (Bethesda, MD). We implanted control rats with placebo pellets. Two pellets (either morphine or placebo; wrapped in nylon) were implanted in each rat under light halothane anesthesia (halothane-oxygen mixture; $1-1.5 \%$ halothane). All electrophysiological testings were limited to 4-6 d after pellet implantation. To study the persistence of the effects of withdrawal, we removed morphine and placebo pellets 1 week before the withdrawal experiments, under light halothane anesthesia.

Statistics. We expressed all group values as mean \pm SEM. We determined statistical significance between control, drug, and washout conditions within each group of cells using one-factor ANOVA for repeated measures, with a post hoc analysis by Newman-Keuls or Fisher PLSD comparison tests. Analysis of the statistical differences, expressed as percent of control within and between groups of cells from untreated, morphine-treated, and sham-operated rats, was done by one-way ANOVA between subjects. We considered $p$ values of $<0.05$ statistically significant.

\section{RESULTS}

\section{Chronic morphine treatment reduces synaptic input-output relationships}

We tested the hypothesis that morphine treatment could change NMDA receptor-mediated synaptic transmission first by measuring the amplitude of NMDA EPSCs evoked by equivalent stimulus intensities before and after chronic treatment. The amplitudes of NAcc NMDA EPSCs from untreated rats increased with increasing stimulus intensities (Fig. 1). Intensities of $>18-20 \mathrm{~V}$ triggered spikes (data not shown in the graph). After morphine treatment, the amplitudes of the synaptic currents, within the same stimulus range, were smaller than those in slices of untreated rats. Statistical analysis showed that the difference was significant at the lowest intensities, that is, at $8 \mathrm{~V}\left[F_{(1,25)}=79.46\right.$; $p<0.001]$ and $10 \mathrm{~V}\left[F_{(1,24)}=4.26 ; p<0.05\right]$. These data suggest that morphine treatment alters NMDA receptor-mediated synaptic transmission either by decreasing the responsiveness of NMDA receptors for glutamate or by decreasing glutamate release. Although the magnitude of this inhibition seems smaller in chronically treated rats than that for acute $\mu$ agonists (Martin et al., 1997a), it is difficult in our experimental conditions to determine whether this difference can be accounted for by alteration of the pre- or postsynaptic effects we observed in naïve animals. We are now addressing this issue by assessing NMDA responsivity in 

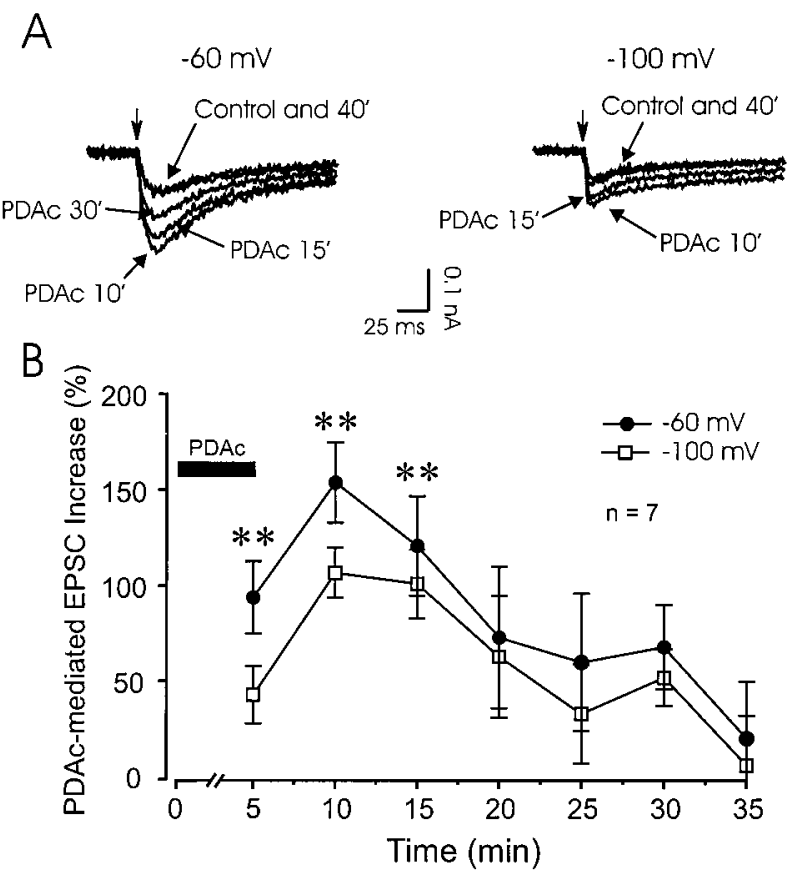

Figure 2. Time course of the $5 \mu \mathrm{M}$ PDAc-evoked enhancement of NMDA EPSCs. $A$, Current traces recorded at $-63 \mathrm{mV}($ left $)$ and -101 $\mathrm{mV}$ (right) holding potentials from an NAcc neuron before (Control) and after PDAc superfusion (10, 15, 30, and $40 \mathrm{~min})$. At both potentials, PDAc enhanced the NMDA EPSC amplitudes with a maximum effect at 10 min. $B$, Mean $(n=7)$ effect of PDAc on NMDA EPSC amplitudes measured at -100 and $-60 \mathrm{mV}$ as a function of time. For NMDA EPSCs measured at $-60 \mathrm{mV}$, the peak effect is reached $10 \mathrm{~min}$ after PDAc superfusion. See text for ${ }^{* *} p$ values. In this and subsequent figures, downward-pointing arrows in the current traces indicate the time of local stimulation to evoke EPSCs.

a freshly isolated NAcc cell preparation that will allow the examination of changes of NMDA receptor affinity.

\section{Chronic morphine decreases PDAc enhancement of NMDA EPSCs}

As noted in the introductory remarks, the NMDA receptor sensitivity to PKC activators is determined by NR2A and/or NR2B subunits. Therefore, we tested the effects of the PKC activator PDAc $(5 \mu \mathrm{M})$ on NMDA EPSC amplitudes in NAcc slices from untreated rats, evoked at approximately -60 and $-100 \mathrm{mV}$ before and after PDAc superfusion (applied for $5 \mathrm{~min}$ ). The enhancement of NMDA EPSCs by PDAc peaked $10 \mathrm{~min}$ after the onset of the superfusion (Fig. 2A). Thirty minutes later, NMDA EPSC amplitudes slowly returned to control values. Although the reason for this decay is not completely understood, some evidence suggests that it is caused by the action of phosphatases that counteract the PKC effect (Lieberman and Mody, 1994; McBain and Mayer, 1994; Wang et al., 1994; Blank et al., 1997). We observed a similar pattern of action for responses recorded at the more hyperpolarized potential (Fig. $2 B$ ), even though the overall potentiation was smaller (Fig. $2 A$, right). Averaged over seven NAcc cells from untreated rats, $5 \mu \mathrm{M}$ PDAc significantly increased NMDA EPSC amplitudes by $157 \pm 21 \%$ of control $10 \mathrm{~min}$ after superfusion when measured at approximately $-60 \mathrm{mV}$ and by $109 \pm 13 \%$ at approximately $-100 \mathrm{mV}$ (Fig. 2B). Statistical analysis showed that NMDA EPSC amplitudes evoked at $-60 \mathrm{mV}$ and measured 5, 10, and 15 min after
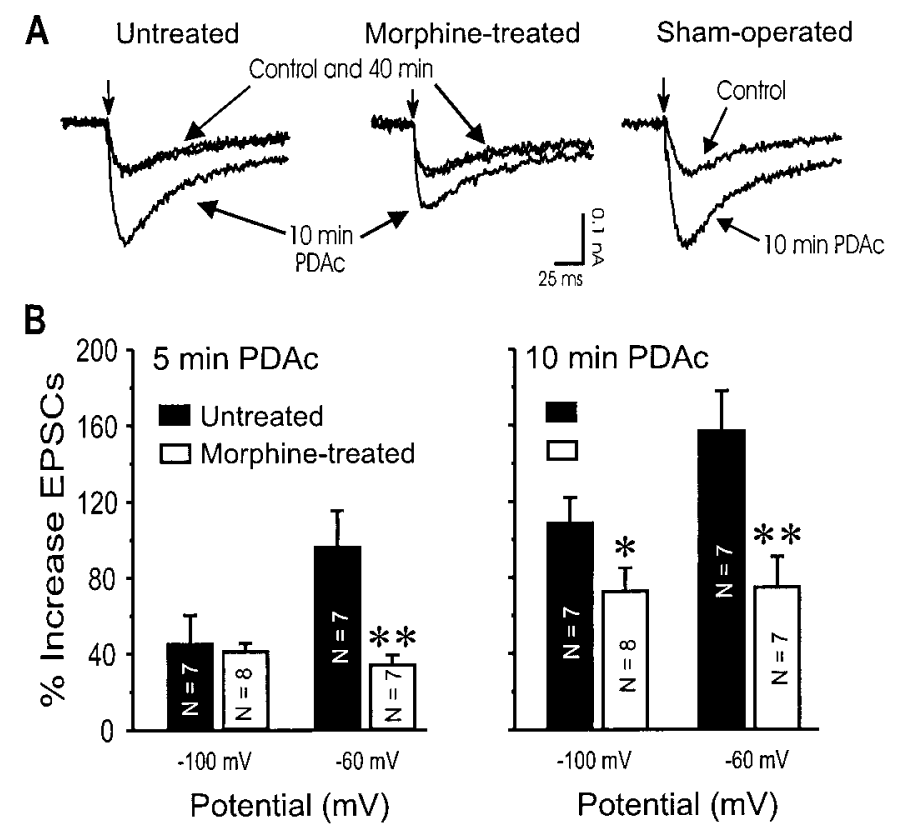

Figure 3. Comparison of the effects of PDAc on NMDA EPSCs in NAcc neurons from untreated, morphine-treated, and sham-operated rats. $A$, Representative traces of NMDA EPSCs from three different neurons (all held at $-60 \mathrm{mV}$ ) from the three treatment groups, before (Control) and 10 and $40 \mathrm{~min}$ after PDAc superfusion. In the neurons from untreated and sham-operated rats, $5 \mu \mathrm{M}$ PDAc increased the amplitudes of NMDA EPSCs by $150 \%$ after 10 min. This effect disappeared 30 min later. After chronic morphine treatment, the PDAc-mediated enhancement is markedly reduced to only $66 \%$ of control levels. $B$, Mean PDAc effects on NMDA EPSC amplitudes measured at -100 and $-60 \mathrm{mV}, 5$ and $10 \mathrm{~min}$ after PDAc superfusion. In NAcc neurons from untreated rats, the PDAc-induced potentiation is voltage-dependent; the NMDA EPSC is almost doubled at $-60 \mathrm{mV}$ versus that at $-100 \mathrm{mV}$. After chronic morphine treatment, the potentiation is significantly reduced $\left[F_{(2,18)}=\right.$ $5.62 ; p<0.0014]$ for the $-60 \mathrm{mV}$ condition only (i.e., in a voltagedependent manner), $10 \mathrm{~min}$ after PDAc superfusion. The statistics were equivalent for sham versus untreated rats. ${ }^{*} p<0.05$; ${ }^{* *} p<0.01$.

PDAc superfusion were significantly higher than that in control conditions ( $p<0.0042,0.0002$, and 0.0004, respectively).

We also compared representative NMDA EPSCs recorded at $-60 \mathrm{mV}$ in three different cells from untreated, morphinetreated, and sham-operated rats before and 10 and 40 min after superfusion of PDAc (Fig. 3A). NMDA EPSC amplitudes were strongly enhanced in untreated and sham-operated rats $10 \mathrm{~min}$ after PDAc superfusion, but this effect was less pronounced in neurons from a morphine-treated rat (Fig. 3A). On average, PDAc boosted the mean NMDA EPSC amplitudes at both holding potentials $(-100$ and $-60 \mathrm{mV})$ and time points $(5$ and $10 \mathrm{~min})$ in slices from untreated and morphine-treated rats (Fig. 3B). However, this effect was markedly reduced after morphine treatment; at approximately $-60 \mathrm{mV}$, PDAc-elicited augmentation of NMDA EPSC amplitudes dropped to $34 \pm 7$ and $74 \pm 18 \%$ of control levels in neurons from morphine-treated rats, 5 and 10 min after PDAc superfusion, respectively. The PDAc effect, at $-60 \mathrm{mV}$ and $5 \mathrm{~min}$ after superfusion, was significantly different between untreated and morphine-treated rats $(p<0.007)$ and between treated and sham rats $(p<0.001)$. However, there was no significant difference between the untreated and sham groups. A similar pattern was observed 10 min after PDAc superfusion.

Because the effect of phorbol ester could be caused by PDAc acting presynaptically (increasing glutamate release) as well as 

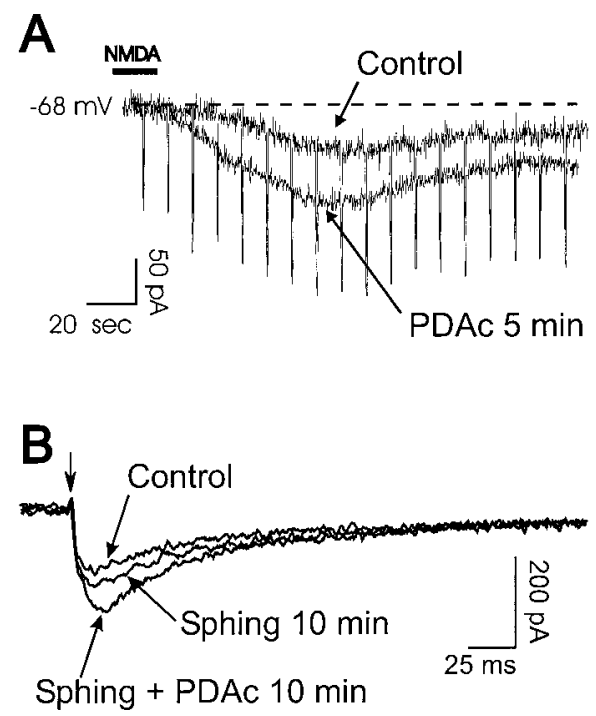

Figure 4. Studies on the site and specificity of PDAc actions. $A$, Inward currents elicited by rapid superf usion of NMDA (initiated at the onset of records; shown by solid horizontal bar) onto NAcc slices from untreated rats in the presence of $15 \mu \mathrm{M}$ bicuculline, $10 \mu \mathrm{M}$ CNQX, and $1 \mu \mathrm{M}$ TTX to block presynaptic release and GABA and non-NMDA receptors. Superimposed polygraph recordings of membrane currents in the same cell held at $-68 \mathrm{mV}$ before and $5 \mathrm{~min}$ after superfusing PDAc are shown. Downward deflections are current responses to brief voltage commands used to monitor membrane conductance. PDAc more than doubled the amplitude of the NMDA current. $B$, Traces of NMDA EPSCs evoked at $-62 \mathrm{mV}$ from the same cell before (Control), $10 \mathrm{~min}$ after sphingosine (Sphing), and $10 \mathrm{~min}$ after sphingosine and PDAc together. Note that sphingosine by itself weakly increased NMDA EPSC amplitude but also strongly attenuated PDAc-mediated enhancement of this current, compared with PDAc without sphingosine (compare with Fig. 2).

postsynaptically, we further examined the locus of its interaction in control slices by rapidly superfusing $60 \mu \mathrm{M}$ NMDA in the presence of $1 \mu \mathrm{M}$ TTX to block glutamate release from terminals. Membrane potential was held at approximately $-65 \mathrm{mV}$ to reduce the voltage-dependent NMDA receptor blockade by $\mathrm{Mg}^{2+}$. PDAc, 5 min after the beginning of superfusion, enhanced the NMDA-elicited inward currents (Fig. 4A). When averaged over three cells, PDAc increased the mean NMDA current by $90 \pm$ $13 \%$. The extent of this PDAc effect is almost equivalent to that for NMDA EPSCs evoked by local stimulation (see Fig. 2B). We also assessed the selectivity of the PDAc effect with sphingosine, a specific PKC inhibitor. Sphingosine $(20 \mu \mathrm{M})$ alone slightly increased NMDA EPSC amplitudes (Fig. 4B). When superfused together with sphingosine, $5 \mu \mathrm{M}$ PDAc enhanced NMDA EPSCs by only $10 \pm 13 \%$, an effect that was not significantly different from that of sphingosine alone. Although we cannot completely rule out some presynaptic action, these data suggest that PDAc enhances NMDA EPSC amplitudes mostly via a postsynaptic mechanism.

\section{Chronic morphine decreases $\mathrm{Mg}^{2+}$ inhibition of NMDA EPSCs}

As with the facilitation of NMDA receptors by PKC, the inhibition by $\mathrm{Mg}^{2+}$ is known to be under the control of NR2 subunits (Monyer et al., 1992, 1994; Ishii et al., 1993; Kawajiri and Dingledine, 1993). To determine the effect of $\mathrm{Mg}^{2+}$, we evoked NMDA EPSCs at holding potentials of approximately $-60 \mathrm{mV}$, first in the presence of a low $\mathrm{Mg}^{2+}$ concentration $(0.3 \mathrm{~mm})$ for $10 \mathrm{~min}$ and then $10 \mathrm{~min}$ after switching to ACSF containing $1.5 \mathrm{~mm}$
A
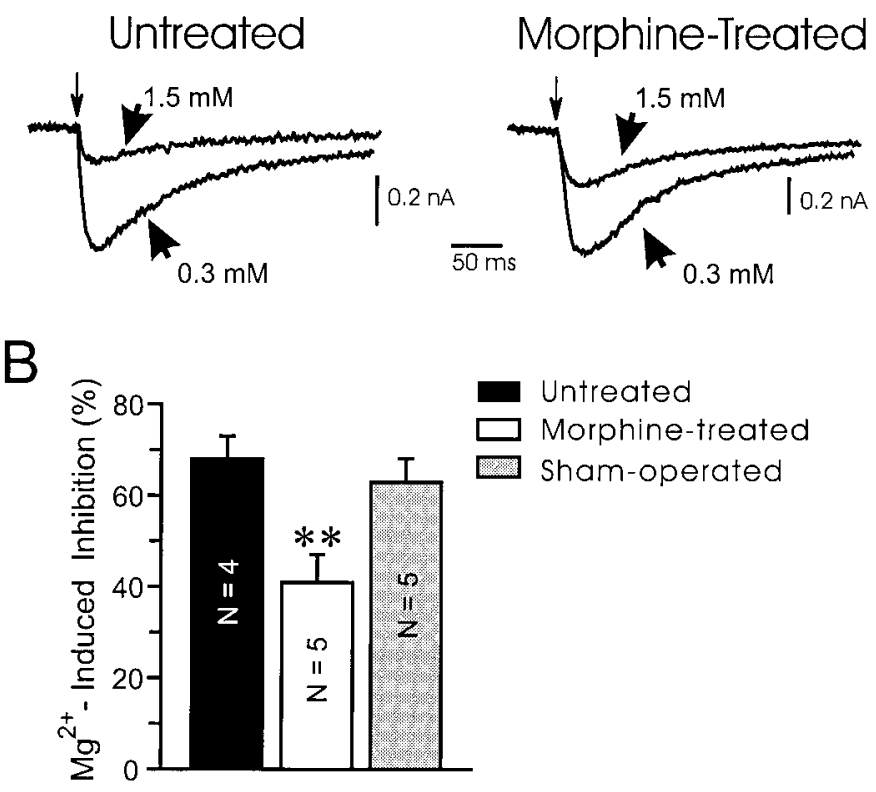

Figure 5. Chronic morphine treatment reduces the $\mathrm{Mg}^{2+}$ sensitivity of NMDA EPSCs in NAcc neurons. $A$, Representative traces of NMDA EPSCs grouped by equivalent amplitudes and similar holding potentials $(-59$ and $-62 \mathrm{mV})$, with superfusion of ACSF containing either low $(0.3$ $\mathrm{mm}$ ) or high (1.5 mM) $\mathrm{Mg}^{2+}$ concentrations. $B$, Mean data from four to five NAcc neurons for each condition, showing significantly reduced $\mathrm{Mg}^{2+}$-mediated inhibition of EPSCs from morphine-treated rats $\left[F_{(2,13)}=9.31 ; p<0.004\right]$. There was no significant difference between neurons of untreated and sham rats. ${ }^{* *} p<0.01$.

$\mathrm{Mg}^{2+}$. As before, we adjusted the stimulus intensity to evoke control NMDA EPSCs with similar amplitudes across different slices (Fig. 5A). Ten minutes after superfusing $1.5 \mathrm{mM} \mathrm{Mg}^{2+}$, the mean amplitude of NMDA EPSCs of untreated and shamoperated rats decreased by $68 \pm 5$ and $60 \pm 5 \%$, respectively, of those in $0.3 \mathrm{~mm} \mathrm{Mg}^{2+}$ (Fig. $5 B$ ). After morphine treatment, the inhibition by $1.5 \mathrm{mM} \mathrm{Mg}^{2+}$ was only $41 \pm 6 \%$. The differences between untreated and morphine-treated rats $\left[F_{(1,7)}=15.02 ; p<\right.$ $0.006]$ and between sham-operated and morphine-treated rats $\left[F_{(1,8)}=11.22 ; p<0.01\right]$ were both significant, whereas the difference between untreated and sham-operated rats was not $(p=0.5)$.

Because slices from morphine-treated rats were constantly exposed to $1 \mu \mathrm{M}$ morphine in the bath to prevent withdrawal, we tested the possibility that the difference in $\mathrm{Mg}^{2+}$ effects between untreated and morphine-treated rats was caused by acute exposure (2-3 hr) of slices to morphine and not by chronic treatment. When the same neuron from an untreated rat (Fig. 6A) was superfused for 2-3 hr with $1 \mu \mathrm{M}$ morphine in the presence of low $(0.3 \mathrm{~mm})$ and high $(1.5 \mathrm{~mm}) \mathrm{Mg}^{2+}$ concentrations at $-59 \mathrm{mV}$, $\mathrm{Mg}^{2+}(1.5 \mathrm{~mm})$ reduced the amplitude of the NMDA EPSCs by $48 \%$ of control $(0.3 \mathrm{~mm})$. When averaged over four cells (Fig. $6 B$ ), the mean high $\mathrm{Mg}^{2+}$-mediated inhibition was $55 \pm 5 \%$ of that in $0.3 \mathrm{mM} \mathrm{Mg}^{2+}$, an effect intermediate between that in untreated $(68 \%)$ and morphine-treated $(41 \%)$ rats. Although the difference between untreated and acute morphine conditions was not statistically significant $(p=0.06)$, that between acute morphine- and chronic morphine-treated rats was significant $(p=0.03)$. These data suggest that acute exposure to morphine tends to alter 

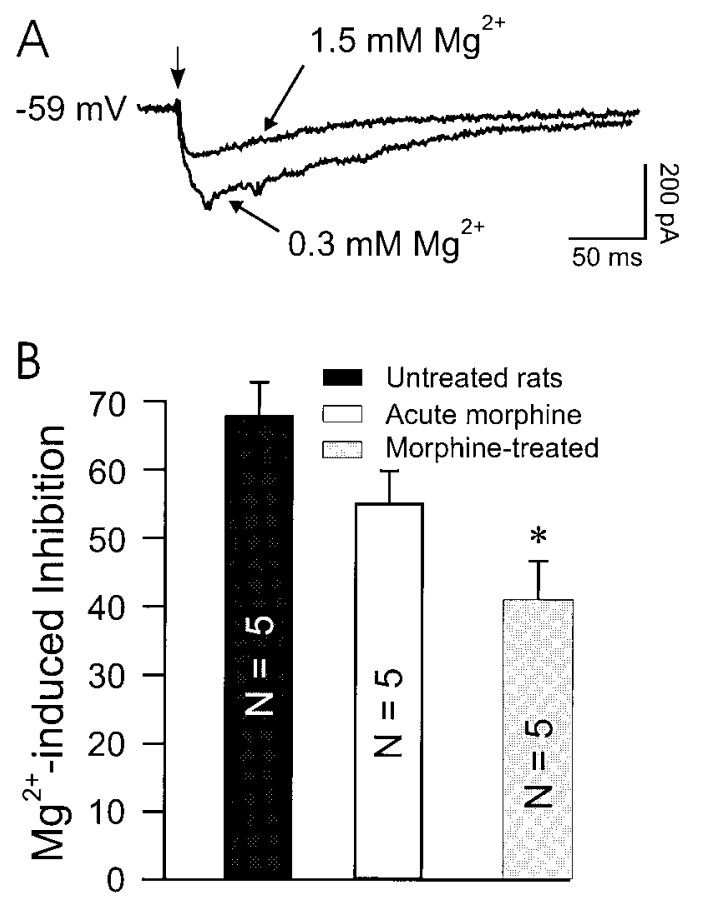

Figure 6. Effects of $\mathrm{Mg}^{2+}$ on NMDA EPSCs from slices of untreated rats after acute exposure $(2-3 \mathrm{hr})$ to morphine $(1 \mu \mathrm{M}) . A$, Individual superimposed traces of NMDA EPSCs recorded in the presence of morphine at $-59 \mathrm{mV}$ during 0.3 and $1.5 \mathrm{mM} \mathrm{Mg}^{2+}$ superfusion. $B$, Mean effects of $\mathrm{Mg}^{2+}$ on NMDA EPSC amplitudes, comparing acute morphine effects with that of untreated and chronic morphine-treated conditions.

NMDA receptor properties but not to the same significant extent that chronic morphine treatment does.

\section{Prolonged morphine withdrawal on $\mathrm{Mg}^{2+}$ and PDAc effects}

We examined the persistence of the effects of chronic morphine by testing for the effects of the high $\mathrm{Mg}^{2+}$ concentration and $5 \mu \mathrm{M}$ PDAc on NMDA EPSCs 1 week after withdrawal from chronic morphine treatment. The inhibition elicited by $\mathrm{Mg}^{2+}$ was still reduced 1 week after withdrawal compared with that in sham rats (Fig. 7A). When averaged over nine and eight cells, $\mathrm{Mg}^{2+} \mathrm{de}-$ creased NMDA EPSC amplitudes from placebo rats by $44 \pm 5 \%$ and in NAcc slices from rats withdrawn from morphine for 1 week by $27 \pm 6 \%$, respectively (Fig. $7 B$ ). The difference between these values was significant $\left[F_{(1,18)}=5.14 ; p=0.038\right]$. Similarly, the enhancement of NMDA EPSC amplitudes by PDAc was still attenuated 1 week after withdrawal compared with that in placebo rats (Fig. $7 C$ ). Thus, PDAc increased the mean NAcc NMDA EPSC amplitudes of placebo rats by $136 \pm 17 \%$ of control versus only $89 \pm 10 \%$ in morphine-withdrawn rats. Again, although the difference of the PDAc-elicited enhancement of mean NMDA EPSC amplitudes between the placebo and withdrawn rats is smaller than that between untreated and chronic morphine-treated rats, nevertheless this difference is statistically significant $\left[F_{(1,15)}=4.91 ; p=0.043\right.$; Fig. $\left.7 D\right]$.

\section{Effect of chronic morphine treatment and withdrawal on the NMDA EPSC inactivation rate}

The kinetics of the NMDA EPSC inactivation also has been shown to be controlled by NR2 subunits (Takahashi et al., 1996; Flint et al., 1997; Gottmann et al., 1997). Therefore, we estimated the kinetics by fitting the decay of the NMDA synaptic responses
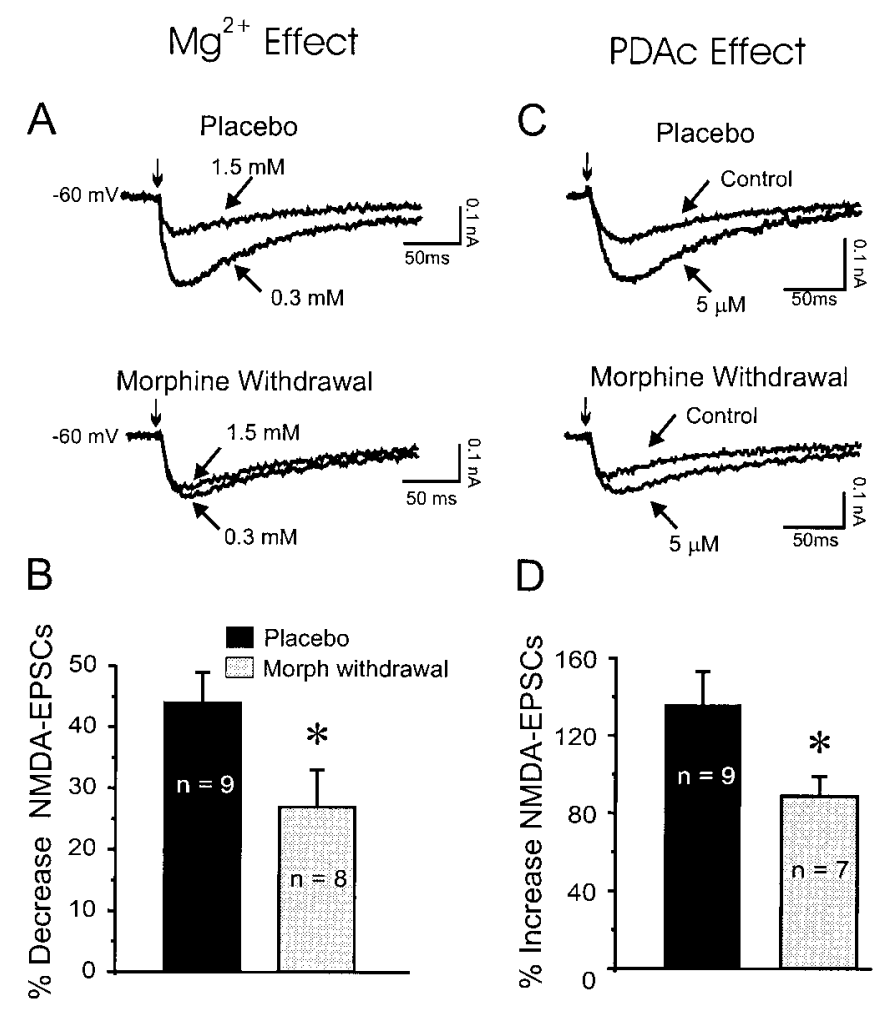

Figure 7. Effect of 1 week withdrawal from morphine on $\mathrm{Mg}^{2+}$ and PDAc effects on accumbens NMDA EPSCs. $A, B$, Chronic withdrawal from morphine treatment reduces the $\mathrm{Mg}^{2+}$ sensitivity of NMDA EPSCs in NAcc neurons. $A$, Representative superimposed traces of NMDA EPSCs at equivalent holding potentials $(-60 \mathrm{mV})$ after superfusion of ACSF containing either low $(0.3 \mathrm{~mm})$ or high $(1.5 \mathrm{~mm}) \mathrm{Mg}^{2+}$ concentrations. $\mathrm{Mg}^{2+}$-induced inhibition is still attenuated 1 week after withdrawal compared with that in placebo rats. $B$, Mean $\mathrm{Mg}^{2+}$-mediated inhibition of NMDA EPSC amplitudes averaged from eight to nine NAcc neurons for each condition. Compared with that in placebo rats, this reduced $\mathrm{Mg}^{2+}$ effect was significant 1 week after withdrawal $\left[F_{(1,16)}=5.1 ;{ }^{*} p=0.038\right]$. $C$, Individual traces of superimposed NMDA EPSCs at equivalent holding potentials $(-60 \mathrm{mV})$ with superfusion of $5 \mu \mathrm{M}$ PDAc. PDAc-evoked enhancement was attenuated 1 week after withdrawal compared with that in placebo rats. $D$, Mean PDAc-mediated facilitation of NMDA EPSC amplitudes from seven to nine NAcc neurons for each condition (legend same as in $B$ ). Compared with that in placebo rats, this effect is still significant 1 week after withdrawal $\left[F_{(1,14)}=4.91 ;{ }^{*} p=0.043\right]$. Morph, Morphine.

between the peak and $260 \mathrm{msec}$ after the stimulation (see Materials and Methods). To draw a meaningful comparison between experimental conditions, we divided the neuronal sample into four groups (Fig. $8 A$ ), according to their mean NMDA EPSC amplitudes $(100,200,300$, and $500 \mathrm{pA})$. The inactivation time constant $(\tau)$ of NMDA EPSCs of neurons from untreated rats was very similar across the four groups, with $\tau$ values ranging between 80 and $100 \mathrm{msec}$ (Fig. $8 B$ ); the mean $\tau$ was $97 \pm 2.5 \mathrm{msec}$. In the chronically treated group, $\tau$ ranged from 68 to $84 \mathrm{msec}$ with a mean of $78.7 \pm 1.8 \mathrm{msec}$. This decrease by morphine treatment was significant for mean NMDA EPSC amplitudes at approximately 200, 300, and $500 \mathrm{pA}(p=0.004,0.0001$, and 0.031 , respectively), but the difference was not significant $(p=0.0504)$ for the smallest group (100 pA). The representative traces of normalized NMDA EPSCs in Figure 8, $C$ and $D$, exemplify the faster inactivation in neurons from morphine-treated rats.

We also examined the persistence of the effects of chronic morphine treatment on the inactivation rate of NMDA EPSCs 1 
A

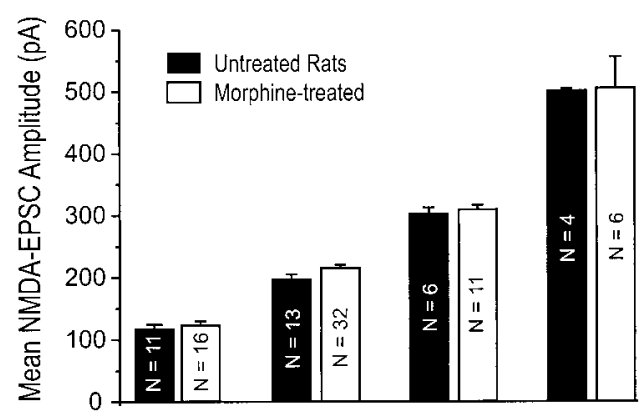

B

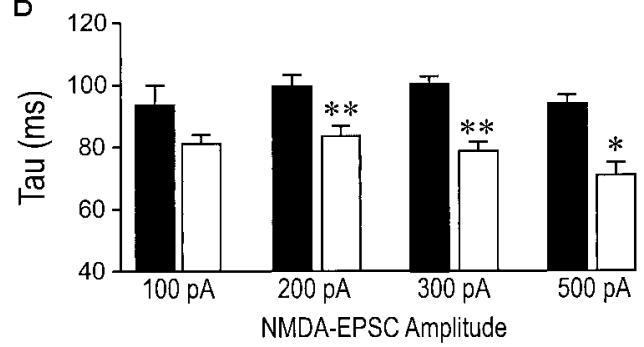

C

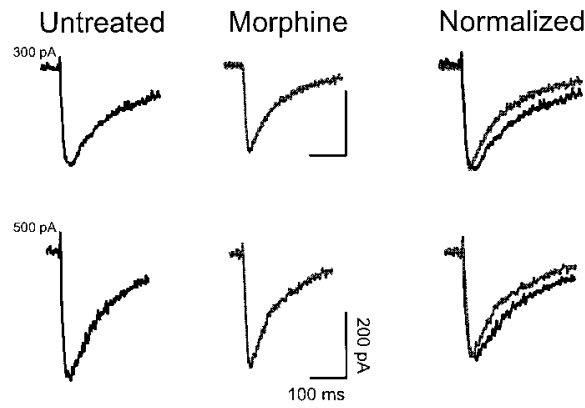

Figure 8. Chronic morphine treatment decreases the NMDA EPSC inactivation rate $(\tau)$. $A$, Mean NAcc NMDA EPSC amplitudes from untreated and morphine-treated rats grouped over four different EPSC amplitudes (100, 200, 300, and 500 pA). $B$, Mean NMDA EPSC inactivation rates measured from the same cells shown in $A$. Note that the $\tau$ inactivation rates are reduced by $\sim 15-20 \%$ after chronic morphine treatment compared with that of controls, regardless of initial EPSC sizes. $C$, $D$, Representative traces of NMDA EPSCs from two different neurons, recorded at approximately $-60 \mathrm{mV}$ using equivalent stimuli and holding potentials and grouped by EPSC size (scaled or normalized EPSCs on the right $)$. Morphine $(1 \mu \mathrm{M})$ was superf used to prevent withdrawal. ${ }^{*} p<0.05$; $* * p<0.01$.

week after morphine withdrawal, measured from neurons grouped according to their mean NMDA EPSC amplitude (100 and $200 \mathrm{pA}$; Fig. 9A). Surprisingly, the mean inactivation $\tau$ values of neurons from withdrawn rats $(80-100 \mathrm{msec})$ were bigger than those of placebo rats $(68-72 \mathrm{msec})$ for both groups of EPSC sizes (Fig. 9B), but only the increase in the first group (100 pA) was significant $(p<0.034)$.

\section{DISCUSSION}

We have studied the properties of NMDA receptor-mediated synaptic transmission in NAcc neurons before and after chronic morphine treatment to uncover possible mechanisms underlying the involvement of this glutamate receptor subtype in some aspects of morphine addiction (Marek et al., 1991; Trujillo and Akil, 1991, 1994; Elliott et al., 1994; Tiseo et al., 1994). The
A
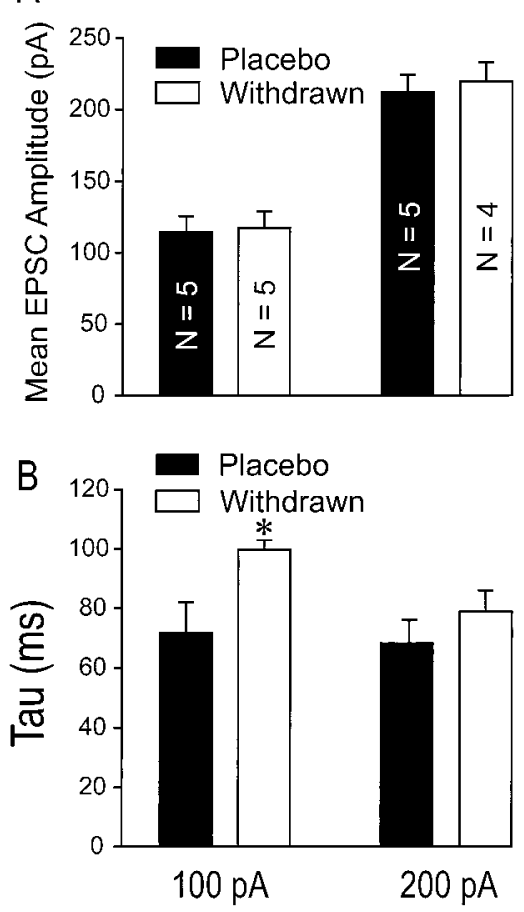

Figure 9. Reversal of chronic morphine effects on EPSC inactivation 1 week after withdrawal. $A$, Mean NMDA EPSC amplitudes from placebo and withdrawn rats grouped over two different EPSC amplitudes (100 and $200 \mathrm{pA}$ ). $B$, Mean NMDA EPSC inactivation rates ( $\tau$ values) measured from the same cells shown in $A$. Note that the $\tau$ values for the morphinewithdrawn EPSCs are now reversed to be larger than that of the sham controls. $n=4-5$ for each group; * $p<0.05$.

pharmacological and kinetic data presented here suggest that chronic morphine treatment decreases: (1) NMDA receptormediated synaptic transmission, (2) the enhancement of NMDA EPSC amplitudes elicited by a PKC activator, (3) $\mathrm{Mg}^{2+}$-elicited inhibition of NMDA EPSCs, and (4) NMDA EPSC inactivation $\tau$ values.

\section{Comparison of native and recombinant NMDA EPSCs}

Early anatomical studies reported that the NR1 subunit is present throughout the brain, whereas NR2A and NR2B subunits are expressed differentially in forebrain structures with almost no expression in other brain regions. Although NR2A expression has been observed in the NAcc, some data suggest that projection neurons of this brain region, as well as those from dorsal striatum, preferentially express NR2B subunits (Buller et al., 1994; Landwehrmeyer et al., 1995). It also is now well established that NR2C and NR2D, expressed mostly in the cerebellum and pons, respectively, are not expressed in NAcc under normal conditions. These anatomical observations suggest that native NAcc NMDA receptors are composed of NR1 and NR2B and maybe to a lesser extent of NR1 and NR2A subunits, although a combination of these three subunits (Chazot and Stephenson, 1997; Luo et al., 1997) is also possible.

The expression of NR2A and NR2B subunits is supported by our electrophysiological data showing that NAcc NMDA EPSCs of naïve rats are markedly enhanced by PDAc, a PKC activator, and strongly inhibited by $\mathrm{Mg}^{2+}$. The vast bulk of our current knowledge on electrophysiological properties of NMDA receptors derives from studies on various expression systems such as 
oocytes and human embryonic kidney cells that provide the advantage of dissecting receptor properties via construction of various combinations of the NMDA receptor subunits (NR1 and NR2A-D) expressed in brain. Thus, several groups have shown that binary NR1/NR2A and NR2B receptors expressed in oocytes display a high sensitivity to PKC activators (Kutsuwada et al., 1992; Meguro et al., 1992). Similarly, $\mathrm{Mg}^{2+}$ inhibition of NMDA currents (Nowak et al., 1984) is almost exclusively displayed by receptors containing NR1/NR2A and NR2B subunits, with no influence of NR1/NR2C and NR2D (Kutsuwada et al., 1992; Monyer et al., 1992).

NAcc NMDA EPSC decays measured in naïve rats also support the absence of NR2C or NR2D subunits in naïve NAcc as indicated by all anatomical studies (see above). Thus, the average decay time (97 $\pm 2.5 \mathrm{msec})$ of NAcc NMDA EPSCs was closer to that of recombinant NR1/NR2A NMDA receptors $(83 \mathrm{msec})$ expressed in human embryonic kidney cells than to that of NR1/ NR2C receptors (319 msec) (Monyer et al., 1992). However, estimation of native receptor subunit composition from decay values alone requires caution, because they vary for the same heteromeric recombinant NMDA receptors from study to study (Monyer et al., 1992; Flint et al., 1997; Gottmann et al., 1997).

\section{Chronic morphine treatment on NMDA receptor- mediated synaptic transmission}

We found that chronic morphine treatment significantly decreased NMDA EPSC amplitudes, $\mathrm{Mg}^{2+}$-elicited inhibition, and PDAc-elicited enhancement of NMDA EPSCs. Previous studies have established that weak $\mathrm{Mg}^{2+}$ block and reduced PKCmediated enhancement of NMDA currents correlated with the presence of NR2C and NR2D subunits (Mori et al., 1993; Grant et al., 1998). As noted above, in normal rat brain neither NR2C nor NR2D is expressed in naïve adult NAcc neurons. Only one study reported that NAcc neurons (somatostatinergic and cholinergic NAcc interneurons, but not projecting GABA neurons) express measurable levels of NR2D (Standaert et al., 1996). One explanation for our result is that chronic morphine treatment could trigger the expression of "dormant" NR2C and/or NR2D subunits that are not expressed in the NAcc of naïve rats. However, our finding of decreased NMDA EPSC inactivation times during chronic treatment apparently contradicts this assumption; as discussed above, reduction of inactivation times is thought to be associated with expression of NR2A rather than NR2C and NR2D. Another explanation is that chronic morphine treatment has multiple effects, inducing the expression of NR2C or NR2D subunits but also increasing the expression of preexisting NR2A subunits. However, Zhu et al. (1999) found no effect of intracerebroventricular chronic morphine treatment on NR2A mRNA expression. Several groups found in NAcc as well as in dorsal striatum that NR2A expression is much less abundant than that for NR2B (Buller et al., 1994; Landwehrmeyer et al., 1995; Wang et al., 1995) or is absent as in human NAcc (Rigby et al., 1996). This predominance of NR2B in naïve animals and the postulated shift toward NR2A could account for the increase of the NMDA EPSC inactivation times after chronic morphine treatment. However, the possible switch to these subunits (NR2A, NR2C, and NR2D) might lead to opposite effects. To address such questions, we are now examining the expression of mRNAs coding for NR2A-D subunits of NAcc medium spiny neurons using singlecell reverse transcription-PCR in an acutely isolated cell preparation.

The change of NMDA receptor-mediated synaptic transmis- sion could occur either pre- or postsynaptically. However, the fact that the PDAc-elicited enhancement of NMDA EPSCs was nearly identical to that of currents evoked by NMDA superfusion in the presence of TTX argues in favor of a postsynaptic locus, at least for the PDAc effect. Nonetheless, we cannot rule out the possibility that decreased glutamate release accounts for some portion of the chronic morphine effects on NMDA EPSC amplitudes and kinetics.

\section{Persistence of chronic morphine effects}

The effects of chronic morphine persisted for 1 week after withdrawal, suggesting that they cannot be explained by the presence of morphine in the bath during the experiments. These longlasting alterations of NMDA receptor properties could contribute to the neuroadaptations known to persist long after the end of opiate intake. It is also interesting that the change in NMDA EPSC kinetics is reversed after withdrawal, whereas inhibitions of $\mathrm{Mg}^{2+}$-evoked inhibition and PDAc-evoked facilitation are still present, although smaller. This divergence of persisting actions may support the hypothesis that $\mathrm{Mg}^{2+}$ - and PDAc-mediated effects reflect a true modification of postsynaptic NMDA receptor subunit composition, whereas the biphasic alteration of EPSC kinetics may derive from summated pre- and postsynaptic effects: with early chronic morphine, presynaptic effects may predominate, whereas long withdrawal leads to a loss of presynaptic effects to reveal an underlying long-term alteration of postsynaptic NMDA receptor subunit composition.

\section{Physiological significance of alterations in NMDA receptor properties}

Chronic morphine treatment has long been known to alter cellular homeostasis. Thus, it downregulates the expression of $\mu$ opiate receptors, stimulates immediate early gene (IEG) expression, and increases cAMP levels. This latter phenomenon may represent a crucial aspect of the effects of chronic morphine, because cAMP is at the crossroads of numerous biochemical processes that control cell homeostasis. There is evidence that increases of cAMP levels may be under the control of an IEG such as that for cAMP response-binding protein (CREB) (LaneLadd et al., 1997). Interestingly, the expression of IEGs like c-jun, jun-B, and CREB may be controlled in part by NMDA receptor activation (Cole et al., 1989; Szekely et al., 1990; Morgan and Linnoila, 1991). Thus, it is tempting to speculate on the control that NMDA receptors could exert on the cAMP upregulation after morphine. In that perspective, the inhibition of NMDA receptor-mediated transmission suggested by the present findings might be regarded as a compensatory mechanism that ultimately diminishes NMDA receptor stimulation of CREB synthesis and therefore the increase of cAMP levels induced by chronic morphine treatment. These effects may occur in concert with the postulated recomposition of NAcc NMDA receptors.

Regardless of the mechanisms involved, the overall effect of chronic morphine should be decreased glutamatergic transmission, exerted both presynaptically (Martin et al., 1999) and now postsynaptically as well. The hypothesis of a depression of the glutamatergic synaptic transmission in NAcc is further substantiated by the recent data of Rogers et al. (1999) showing that the deficit of decision making by human opiate abusers can be correlated with damage of the orbitofrontal subregion of the prefrontal cortex that contributes most of the NAcc glutamate afferents. This reduced glutamatergic transmission, along with the increased release of GABA reported for accumbens neurons 
(Chieng and Williams, 1998), would depress neuronal excitability. These concerted effects of chronic morphine on glutamate- and GABA-mediated synaptic transmission could underlie some of the changes that occur during the transition to drug addiction (Koob et al., 1998) as well as the rewarding properties of opioids.

In view of the role of NAcc in drug reward, it is tempting to suggest that these long-lasting changes in excitability of NAcc neurons may contribute to various phenomena such as increased opiate self-administration observed recently in dependent rats (Carrera et al., 1999), as well as other forms of enhanced behavioral responsiveness to opiates (Shippenberg et al., 1996). Thus, rats may work to inhibit their accumbens neurons, and chronic administration of opioids may facilitate such inhibition. Because the enhanced reward associated with opiate dependence could derive from both sensitization and tolerance, further studies are necessary to determine whether the effects observed in this study account for either phenomena.

\section{REFERENCES}

Blank T, Nijholt I, Teichert U, Kugler H, Behrsing H, Fienberg A, Greengard P, Spiess J (1997) The phosphoprotein DARPP-32 mediates cAMP-dependent potentiation of striatal $N$-methyl-D-aspartate responses. Proc Natl Acad Sci USA 94:14859-14864.

Buller AL, Larson HC, Schneider BE, Beaton JA, Morrisett RA, Monaghan DT (1994) The molecular basis of NMDA receptor subtypes: native receptor diversity is predicted by subunit composition. J Neurosci 14:5471-5484.

Burnashev N, Schoepfer R, Monyer H, Ruppersberg JP, Gunther W, Seeburg PH, Sakmann B (1992) Control by asparagine residues of calcium permeability and magnesium blockade in the NMDA receptor. Science 257:1415-1419.

Burnashev N, Zhou Z, Neher E, Sakmann B (1995) Fractional calcium currents through recombinant GluR channels of the NMDA, AMPA and kainate receptor subtypes. J Physiol (Lond) 485:403-418.

Carrera MRA, Schulteis G, Koob GF (1999) Heroin self-administration in dependent wistar rats: increased sensitivity to naloxone. Psychopharmacology (Berl) 144:111-120.

Chazot PL, Stephenson FA (1997) Molecular dissection of native mammalian forebrain NMDA receptors containing the NR1 C2 exon: direct demonstration of NMDA receptors comprising NR1, NR2A, and NR2B subunits within the same complex. J Neurochem 69:2138-2144.

Chen XY, Michaelis ML, Michaelis EK (1997) Effects of chronic ethanol treatment on the expression of calcium transport carriers and NMDA/glutamate receptor proteins in brain synaptic membranes. J Neurochem 69:1559-1569.

Chieng B, Williams JT (1998) Increased opioid inhibition of GABA release in nucleus accumbens during morphine withdrawal. J Neurosci 18:7033-7039.

Cole AJ, Saffen DW, Baraban JM, Worley PF (1989) Rapid increase of an immediate early gene messenger RNA in hippocampal neurons by synaptic NMDA receptor activation. Nature 340:474-476.

Elliott K, Minami N, Kolesnikov YA, Pasternak GW, Inturrisi CE (1994) The NMDA receptor antagonists, LY274614 and MK-801, and the nitric oxide synthase inhibitor, NG-nitro-L-arginine, attenuate analgesic tolerance to the mu-opioid morphine but not to kappa opioids. Pain 56:69-75.

Fitzgerald LW, Ortiz J, Hamedani AG, Nestler EJ (1996) Drugs of abuse and stress increase the expression of GluR1 and NMDAR1 glutamate receptor subunits in the rat ventral tegmental area: common adaptations among cross-sensitizing agents. J Neurosci 16:274-282.

Flint AC, Maisch US, Weishaupt JH, Kriegstein AR, Monyer H (1997) NR2A subunit expression shortens NMDA receptor synaptic currents in developing neocortex. J Neurosci 17:2469-2476.

Follesa P, Ticku MK (1996) Chronic ethanol-mediated up-regulation of the $N$-methyl-D-aspartate receptor polypeptide subunits in mouse cortical neurons in culture. J Biol Chem 271:13297-13299.

Fundytus ME, Coderre TJ (1997) Attenuation of precipitated morphine withdrawal symptoms by acute icv administration of a group II mGluR agonist. Br J Pharmacol 121:511-514.

Fundytus ME, Schiller PW, Shapiro M, Weltrowska G, Coderre TJ (1995) Attenuation of morphine tolerance and dependence with the highly selective $\delta$-opioid receptor antagonist TIPP[psi]. Eur J Pharmacol 286:105-108.

Fundytus ME, Ritchie J, Coderre TJ (1997) Attenuation of morphine withdrawal symptoms by subtype-selective metabotropic glutamate receptor antagonists. Br J Pharmacol 120:1015-1020.

Gallagher MJ, Huang H, Pritchett DB, Lynch DR (1996) Interactions between ifenprodil and the NR2B subunit of the $N$-methyl-D-aspartate receptor. J Biol Chem 271:9603-9611.

Gottmann K, Mehrle A, Gisselmann G, Hatt H (1997) Presynaptic control of subunit composition of NMDA receptors mediating synaptic plasticity. J Neurosci 17:2766-2774.

Grant ER, Bacskai BJ, Anegawa NJ, Pleasure DE, Lynch DR (1998) Opposing contributions of NR1 and NR2 to protein kinase C modulation of NMDA receptors. J Neurochem 71:1471-1481.

Groenewegen HJ, Wright CI, Beijer AV (1996) The nucleus accumbens: gateway for limbic structures to reach the motor system? Prog Brain Res 107:485-511.

Heimer L, Alheid GF, de Olmos JS, Groenewegen HJ, Haber SN, Harlan RE, Zahm DS (1997) The accumbens: beyond the core-shell dichotomy. J Neuropsychiatry Clin Neurosci 9:354-381.

Ishii T, Moriyoshi K, Sugihara H, Sakurada K, Kadotani H, Yokoi M, Akazawa C, Shigemoto R, Mizuno N, Masu M, Nakanishi S (1993) Molecular characterization of the family of the $N$-methyl-D-aspartate receptor subunits. J Biol Chem 268:2836-2843.

Jeziorski M, White F, Wolf ME (1994) MK-801 prevents the development of behavioral sensitization during repeated morphine administration. Synapse 16:137-147.

Kalluri HS, Mehta AK, Ticku MK (1998) Up-regulation of NMDA receptor subunits in rat brain following chronic ethanol treatment. Mol Brain Res 58:221-224.

Kawajiri S, Dingledine R (1993) Multiple structural determinants of voltage-dependent magnesium block in recombinant NMDA receptors. Neuropharmacology 32:1203-1211.

Kest B, McLemore G, Kao B, Inturrisi CE (1997) The competitive $\alpha$-amino-3-hydroxy-5-methylisoxazole-4-propionate receptor antagonist LY293558 attenuates and reverses analgesic tolerance to morphine but not to delta or kappa opioids. J Pharmacol Exp Ther 283:1249-1255.

Koob GF (1992) Drugs of abuse: anatomy, pharmacology and function of reward pathways. Trends Pharmacol Sci 13:177-184.

Koob GF, Maldonado R, Stinus L (1992) Neural substrates of opiate withdrawal. Trends Neurosci 15:186-191.

Koob GF, Sanna PP, Bloom FE (1998) Neuroscience of addiction. Neuron 21:467-476.

Kuner T, Schoepfer R (1996) Multiple structural elements determine subunit specificity of $\mathrm{Mg} 2+$ block in NMDA receptor channels. J Neurosci 16:3549-3558.

Kutsuwada T, Kashiwabuchi N, Mori H, Sakimura K, Kushiya E, Araki K, Megura H, Masaki H, Kumanidi T, Arakawa M, Mishima M (1992) Molecular diversity of the NMDA receptor channel. Nature 358:36-41.

Landwehrmeyer GB, Standaert DG, Testa CM, Penney Jr JB, Young AB (1995) NMDA receptor subunit mRNA expression by projection neurons and interneurons in rat striatum. J Neurosci 15:5297-5307.

Lane-Ladd SB, Pineda J, Boundy VA, Pfeuffer T, Krupinski J, Aghajanian GK, Nestler EJ (1997) CREB (cAMP response element-binding protein) in the locus coeruleus: biochemical, physiological, and behavioral evidence for a role in opiate dependence. J Neurosci 17:7890-7901.

Lieberman DN, Mody I (1994) Regulation of NMDA channel function by endogenous $\mathrm{Ca} 2+-$-dependent phosphatase. Nature 369:235-239.

Luo J, Wang Y, Yasuda RP, Dunah AW, Wolfe BB (1997) The majority of $N$-methyl-D-aspartate receptor complexes in adult rat cerebral cortex contain at least three different subunits (NR1/NR2A/NR2B). Mol Pharmacol 51:79-86.

Marek P, Ben-Eliyahu S, Gold M, Liebeskind JC (1991) Excitatory amino acid antagonists (kynureate acid and MK-801) attenuate the development of morphine tolerance in the rat. Brain Res 547:77-81.

Martin G, Nie Z, Siggins GR (1997a) $\mu$-Opioid receptors modulate NMDA receptor-mediated responses in nucleus accumbens neurons. J Neurosci 17:11-22.

Martin G, Nie Z, Siggins GR (1997b) Metabotropic glutamate receptors regulate $N$-methyl-D-Aspartate-mediated synaptic transmission in nucleus accumbens. J Neurophysiol 78:3028-3038. 
Martin G, Przewlocki R, Siggins GR (1999) Chronic morphine treatment selectively augments metabotropic glutamate receptor-induced inhibition of $N$-methyl-D-aspartate receptor-mediated neurotransmission in nucleus accumbens. J Pharmacol Exp Ther 288:30-35.

McBain CJ, Mayer ML (1994) N-Methyl-D-aspartic acid receptor structure and function. Physiol Rev 74:723-760.

Meguro H, Mori H, Araki K, Kushiya E, Kutsuwada T, Yamazaki M, Kumanishi T, Arakawa M, Sakimura K, Mishima M (1992) Functional characterization of a heteromeric NMDA receptor channel expressed from cloned cDNAs. Nature 357:70-74.

Monyer H, Sprengel R, Schoepfer R, Herb A, Higuchi M, Lomeli H, Burnashev N, Sakmann B, Seeburg PH (1992) Heteromeric NMDA receptors: molecular and functional distinction of subtypes. Science 256:1217-1221.

Monyer H, Burnashev N, Laurie DJ, Sakmann B, Seeburg PH (1994) Developmental and regional expression in the rat brain and functional properties of four NMDA receptors. Neuron 12:529-540.

Morgan PF, Linnoila M (1991) Regional induction of c-fos mRNA by NMDA: a quantitative in-situ hybridization study. NeuroReport $2: 251-254$.

Mori H, Yamakura T, Masaki H, Mishina M (1993) Involvement of the carboxyl-terminal region in modulation by TPA of the NMDA receptor channel. NeuroReport 4:519-522.

Nowak L, Bregestovski P, Ascher P, Herbert A, Prochiantz A (1984) Magnesium gates glutamate-activated channels in mouse central neurones. Nature 307:462-465.

Rigby M, Le Bourdelles B, Heavens RP, Kelly S, Smith D, Butler A, Hammans R, Hills R, Xuereb JH, Hill RG, Whiting RJ, Sirinathsinghji DJS (1996) The messenger RNAs for the $N$-methyl-D-aspartate receptor subunits show region-specific expression of different subunit composition in the human brain. Neuroscience 73:429-447.

Rogers RD, Everitt BJ, Baldacchino A, Blackshaw AJ, Swainson RA, Wynne K, Baker NB, Hunter J, Carthy T, Booker E, London M, Deakin JFW, Sahakian BJ, Robbins TW (1999) Dissociable deficits in the decision-making cognition of chronic amphetamine abusers, opiate abusers, patients with focal damage to prefrontal cortex, and tryptophan-depleted normal volunteers: evidence for monoaminergic mechanisms. Neuropsychopharmacology 20:322-339.

Shippenberg TS, Heidbreder C, Lefevour A (1996) Sensitization to the conditioned rewarding effects of morphine: pharmacology and temporal characteristics. Eur J Pharmacol 299:33-39.

Snell LD, Nunley KR, Lickteig RL, Browning MD, Tabakoff B, Hoffman PL (1996) Regional and subunit specific changes in NMDA receptor mRNA and immunoreactivity in mouse brain following chronic ethanol ingestion. Mol Brain Res 40:71-78.

Standaert DG, Landwehrmeyer GB, Kerner JA, Penney Jr JB, Young AB (1996) Expression of NMDAR2D glutamate receptor subunit mRNA in neurochemically identified interneurons in the rat neostriatum, neocortex and hippocampus. Mol Brain Res 42:89-102.

Szekely AM, Costa E, Grayson DR (1990) Transcriptional program coordination by $N$-methyl-D-aspartate-sensitive glutamate receptor stimulation in primary cultures of cerebellar neurons. Mol Pharmacol 38:624-633.

Takahashi T, Feldmeyer D, Suzuki N, Onodera K, Cull-Candy SG, Sakimura K, Mishina M (1996) Functional correlation of NMDA receptor epsilon subunits expression with the properties of singlechannel and synaptic currents in the developing cerebellum. J Neurosci 16:4376-4382.

Tiseo PJ, Cheng J, Pasternak GW, Inturrisi CE (1994) Modulation of morphine tolerance by the competitive $N$-methyl-D-aspartate receptor antagonist LY274614: assessment of opioid receptor changes. J Pharmacol Exp Ther 268:195-201.

Trujillo KA (1995) Effects of noncompetitive $N$-methyl-D-aspartate receptor antagonists on opiate tolerance and physical dependence. Neuropsychopharmacology 13:301-307.

Trujillo KA, Akil H (1991) Inhibition of morphine tolerance and dependence by the NMDA receptor antagonist MK-801. Science 251:85-87.

Trujillo KA, Akil H (1994) Inhibition of opiate tolerance by noncompetitive $N$-methyl-D-aspartate receptor antagonists. Brain Res 633:178-188.

Wang JKT, Thukral V (1996) Presynaptic NMDA receptors display physiological characteristics of homomeric complexes of NR1 subunits that contain the exon 5 insert in the N-terminal domain. J Neurochem 66:865-868.

Wang L-Y, Orser BA, Brautigan DL, MacDonald JF (1994) Regulation of NMDA receptors in cultured hippocampal neurons by protein phosphatases 1 and 2A. Nature 369:230-232.

Wang YH, Bosy TZ, Yasuda RP, Grayson DR, Vicini S, Pizzorusso T, Wolfe BB (1995) Characterization of NMDA receptor subunitspecific antibodies: distribution of NR2A and NR2B receptor subunits in rat brain and ontogenic profile in the cerebellum. J Neurochem 65:176-183.

Williams K, Zappia AM, Pritchett DB, Shen YM, Molinoff PB (1994) Sensitivity of the $N$-methyl-D-aspartate receptor to polyamines is controlled by NR2 subunits. Mol Pharmacol 45:803-809.

Zahm DS, Brog JS (1992) On the significance of subterritories in the accumbens part of the ventral striatum. Neuroscience 50:751-767.

Zhu H, Ho IK (1998) NMDA-R1 antisense oligonucleotide attenuates withdrawal signs from morphine. Eur J Pharmacol 352:151-156.

Zhu H, Jang CG, Ma T, Oh S, Rockhold RW, Ho IK (1999) Region specific expression of NMDA receptor NR1 subunit mRNA in hypothalamus and pons following chronic morphine treatment. Eur J Pharmacol 365:47-54. 